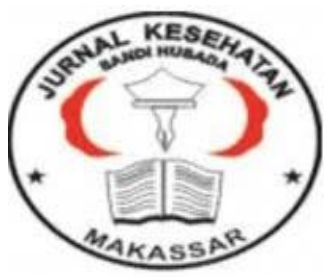

\author{
Jurnal Ilmiah Kesehatan Sandi Husada \\ hhttps://akper-sandikarsa.e-journal.id/JIKSH \\ Volume 9 Nomor 2 Desember 2020, pp 654-664 \\ p-ISSN: 2354-6093 dan e-ISSN: 2654-4563 \\ DOI: $10.35816 /$ jiskh.v10i2.380
}

\title{
Sosiodemografi dengan Kepatuhan Peserta Prolanis Di Puskesmas Kedaton Bandar Lampung
}

Sociodemography with Compliance of Prolanis Participants at the Kedaton Health Center in Bandar Lampung

\author{
Gayatri Putri' ${ }^{1}$, Rita Agustina ${ }^{2}$, Festy Ladyani Mustofa ${ }^{3}$ \\ ${ }^{1}$ Program Studi Kedokteran Universitas Malahayati \\ ${ }^{2}$ Dosen Fakultas Kedokteran Universitas Malahayati \\ ${ }^{3}$ Departemen Gizi Medik Fakultas Kedokteran Universitas Malahayati
}

\section{Artikel info}

Artikel history:

Received; Juni 2020

Revised: Agustus 2020

Accepted; Agustus 2020

\begin{abstract}
Abstrak
Latar Belakang : Prolanis adalah sistem pelayanan kesehatan proaktif terintegrasi yang melibatkan peserta, Fasilitas Kesehatan dan BPJS kesehatan dalam rangka pemeliharaan kesehatan bagi peserta BPJS Kesehatan yang menderita penyakit kronis termasuk diabetes tipe 2 untuk mencapai kualitas hidup yang optimal. Tujuan: mengetahui hubungan sosiodemografi dengan kepatuhan peserta PROLANIS di Puskesmas Kedaton Bandar Lampung. Metode: Penelitian ini merupakan penelitian observasi analitik dengan pendekatan cross sectional. Sumber data penelitian data yang diperoleh dari kuesioner dan catatan buku kehadiran pasien peserta PROLANIS di Puskesmas Kedaton Bandar Lampung. Populasi 250 pasien peserta PROLANIS. Sampel terdiri atas 72 peserta PROLANIS. Pengumpulan data pada bulan februari 2020. Analisis melalui analisis univariat dan bivariat. Hasil: bahwa tidak ada hubungan pada usia dengan hasil $p=0,09$ ( $p>0,05)$, jenis kelamin dengan hasil $p=0,183(p>0,05)$ dan adanya hubungan pada pendidikan dengan hasil $p=0.000(p<0,05)$, pekerjaan dengan hasil $p=0,022(p<0,05)$, dukungan keluarga dengan hasil $p=0,000 \quad(p<0,05)$. Hubungan sosiodemografi dengan kepatuhan peserta PROLANIS di Puskesmas Kedaton Bandar Lampung. Kesimpulan: tidak terdapat hubungan antara usia dan jenis kelamin dengan kepatuhan mengikuti Prolanis dan terdapat hubungan antara pendidikan, pekerjaan, dukungan keluarga dengan kepatuhan mengikuti Prolanis.
\end{abstract}

\section{Abstract.}

Background: Prolanis is an integrated proactive health service system that involves participants, Health Facilities and BPJS health in the context of health care for BPJS Health 
participants who suffer from chronic diseases including type 2 diabetes to achieve optimal quality of life. Objective: to determine the sociodemographic relationship with the compliance of PROLANIS participants at the Kedaton Bandar Lampung Health Center. Method: This research was an analytic observational study with cross sectional approach. Data sources of research data obtained from questionnaires and attendance book records of patients participating in PROLANIS at the Kedaton Health Center in Bandar Lampung. Population of 250 patients participating in PROLANIS. The sample consisted of 72 PROLANIST participants. Data collection in February 2020. Analysis through univariate and bivariate analysis. Results: that there was no relationship in age with results $p=0.09$ ( $p>0.05$ ), sex with results $p=0.183$ ( $p>0.05)$ and there was a relationship in education with results $p=0.000$ ( $p<0.05)$, work with results $p=0.022$ ( $p$ $<0.05)$, family support with results $p=0,000(p<0.05)$. The sociodemographic relationship with the compliance of PROLANIS participants at the Kedaton Health Center in Bandar Lampung. Conclusion: there is no relationship between age and gender with adherence to Prolanis and there is a relationship between education, employment, family support with adherence to follow Prolanis.

Keywords:

Sociodemography;

Compliance;

Prolanis;
Coresponden author:

Email: putrigayatrii035@gmail.com

artikel dengan akses terbuka dibawah lisensi CC BY 4.0

\section{Pendahuluan}

Penyakit tidak menular (PTM) merupakan penyakit degeneratif, yang terjadi secara perlahaan, semakin lama semakin serius dan terjadi dalam jangka waktu yang lama atau disebut juga penyakit kronis. Walau pun tidak semua penyakit kronis mengancam jiwa, tetapi akan menjadi beban ekonomi bagi individu, keluarga, dan komunitas secara keseluruhan. Menurut data riset kesehatan daerah (Riskesdas) pada tahun 2007, di Indonesia tercatat penyebab kematian tertinggi adalah akibat stroke $(15,4 \%)$, yang diikuti hipertensi, kanker, diabetes dan juga penyakit paru obstruktif kronis (Prastinawati.N.T, 2017).

Di Indonesia terjadi peningkatan jumlah PTM yaitu dari 41.7\% menjadi 59.5\%. Indonesia prevalensi hipertensi pada tahun 2007 yaitu sebesar 31.7\% angka tersebut mengalami penurunan pada tahun 2013 yaitu sebesar 25,8\% diperkirakan penurunan bisa memberikan hasil berbeda karena perbedaan alat ukur dan kemungkinan lainnya, namun terjadi peningkatan prevalensi hipertensi berdasarkan hasil wawancara dari 7,6\% pada tahun 2007 menjadi 9.5\% pada tahun 2013 (Kemenkes, 2013). Sedangkan untuk prevalensi DM meningkat sebesar 2.1\% ditahun 2013 dibandingkan 1.1\% pada tahun 2007. Berdasarkan penelitian tersebut diperkirakan di Indonesia terdapat 3,7 juta penderita DM, dimana 69,6\% diantaranya belum terdiagnosis. Namun hipertensi dan DM 
masih berada pada tingkatan teratas kejadian PTM dari kasus lain yang ditemukan (Kemenkes, 2013).

Agar menindak lanjuti masalah tersebut, pemerintah melalui BPJS Kesehatan bekerja sama dengan pihak pelayanan fasilitas kesehatan merancang suatu program yang tergabung dengan model pengelolaan penyakit kronis bagi peserta penderita penyakit kronis yang dikenal dengan "PROLANIS" atau "Program Pengelolaan Penyakit Kronis". Aktivitas atau bentuk kegiatan di dalam prolanis yang dilaksanakan setiap sekali dalam sebulan ini mencakup senam, edukasi kelompok, konsultasi medis atau berbagi pengalaman antar peserta prolanis, pemeriksaan kesehatan oleh dokter, pemeriksaan gula darah dan pengobatan (Wicaksono \& Fajriyah, 2018). Penyakit kronis yang dimaksud dalam program Prolanis BPJS ialah penyakit diabetes mellitus tipe II dan penyakit hipertensi, dengan bentuk aktivitas pelaksanaan yang meliputi konsultasi medis/ edukasi, homevisit, aktivitas klub dan pemantauan status kesehatan dengan penanggung jawab program pada kantor cabang BPJS kesehatan bagian manajemen pelayanan primer (Fathoni, 2017).

Di Kota Bandar Lampung sendiri, program Prolanis BPJS kesehatan yang telah diselenggarakan di puskesmas seluruh Bandar Lampung yaitu berjumlah 30 unit puskesmas telah dilaksanakan sesuai aturan yang berlaku. Dari seluruh Puskesmas yang ada di Bandar Lampung, ada beberapa Puskesmas yang mendapatkan penilaian baik salah satunya adalah Puskesmas Susunan Baru dan Puskesmas Kedaton. Mengingat bahwa penyakit kronis yang dimaksud oleh BPJS Kesehatan ini ialah penyakit yang bisa dikatakan tidak akan pernah sembuh tetapi bisa selalu dipantau dan dijaga tingkat keparahannya, oleh sebab itu program PROLANIS ini sangat penting untuk dilaksanakan (Fathoni, 2017). Pada penelitian sebelumnya yang dilakukan di Puskesmas Pekurun Lampung Utara, dengan klub Prolanis yang baru berdiri pada tahun 2014 dengan total peserta sebanyak 141 orang. Namun dilihat dari segi kunjungan rutin ke klub Prolanis jumlahnya selalu berfluktuasi. Pada tahun 2014 terdapat 90\% (122 peserta) mengikuti kegiatan secara rutin, namun terjadi penurunan pada tahun 2015 menjadi 65\% (107 peserta). Pada bulan Januari-April 2016, hanya terdapat 40\% (50 peserta) saja yang mengikuti kegiatan Prolanis ini. Rendahnya angka kunjungan peserta Prolanis di Puskesmas Pekurun Lampung Utara dapat disebabkan oleh faktor perilaku dan juga gaya hidup peserta (Wulandari \& Antoni, 2017).

Menurut Lawrence Green dalam buku (Notoatmodjo, 2012), prilaku kesehatan terbagi dalam tiga teori penyebab masalah kesehatan yang diantaranya: Faktor predisposisi (predisposing factors) merupakan factor yang mempredisposisi terjadinya perilaku seseorang, anatara lain usia, jenis kelamin, pengetahuan, sikap, keyakinan, kepercayaan, nilai-nilai, tradisi; Faktor pemungkin (Enabling factors) merupakan faktor yang memfasilitasi tindakan artinya adalah sarana dan prasarana atau fasilitas untuk terjadinya prilaku kesehatan antara lain pendidikan, pekerjaan, sosial ekonomi, jarak tempuh, kesesuaian waktu; Faktor penguat (Reinforcing factors) merupakan faktor-faktor yang mendorong atau memperkuat terjadinya prilaku seperti dukungan keluarga (Wulandari \& Antoni, 2017). Berdasarkan uraian di atas, peneliti tertarik untuk mengadakan penelitian tentang Hubungan Sosiodemografi Dengan Kepatuhan Peserta PROLANIS di Puskesmas Kedaton Bandar Lampung Tahun 2019.

\section{Metode}

Penelitian ini menggunakan metode analitik observasional. Penelitian ini dilakukan pada bulan November 2019 bertempat di Puskesmas Kedaton Kota Bandar Lampung setelah mendapatkan ethical clearance dari Universitas Malahayati. Populasi dalam penelitian ini 
adalah peserta PROLANIS yang mengikuti kegiatan PROLANIS di Puskesmas Kedaton Kota Bandar Lampung pada periode 2019, yaitu sebanyak 250 pasien peserta PROLANIS. Pengambilan sampel dilakukan dengan teknik quota sampling, banyaknya sampel dihitung menggunakan rumus slovin, dengan besar taraf keyakinan $90 \%$ akan kebenaran hasil, dan taraf signifikasi 0,1. Dengan rumus tersebut dihasilkan besar sempel yaitu 71,428 dan dibulatkan menjadi 72 sampel peserta PROLANIS di Puskesmas Kedaton Bandar Lampung.

Analisis statistik untuk mengolah data yang diperoleh akan menggunakan program SPSS. Analisis data dengan menggunakan analisis univariat bertujuan untuk menjelaskan atau mendeskripsikan karakteristik setiap variabel, pada umumnya dalam analisis ini hanya menghasilkan distribusi frekuensi dan persentase dari tiap variabel. Dan analsis bivariat yang digunakan untuk mengetahui adanya hubungan antara variabel bebas dengan variabel terikat dengan menggunakan uji statistic Chi Square.

\section{Hasil Dan Pembahasan}

Tabel.1 Frekuensi Responden Peserta Prolanis Berdasarkan Karakteristik Sosiodemografi

\begin{tabular}{lcc}
\hline \multicolumn{1}{c}{ Karakteristik } & Frekuensi & Presentase (\%) \\
\hline Umur & & \\
$\quad$ Dewasa (20-59 tahun) & 38 & $52.8 \%$ \\
$\quad$ Lansia ( $\geq 60$ Thn) & 34 & $47.2 \%$ \\
\hline Jenis Kelamin & 16 & $22.2 \%$ \\
$\quad$ Laki-laki & 56 & $77.8 \%$ \\
$\quad$ Perempuan & & \\
Tingkat Pendidikan & 25 & $34.7 \%$ \\
$\quad$ Rendah (SD, SMP) & 47 & $65.3 \%$ \\
$\quad$ Tinggi ( SMA, PT) & 22 & $30.6 \%$ \\
\hline Pekerjaan & 50 & $69.4 \%$ \\
$\quad$ Tidak Bekerja & & \\
$\quad$ Bekerja & 57 & $79.2 \%$ \\
\hline Dukungan Keluarga & 15 & $20.8 \%$ \\
$\quad$ Positif &
\end{tabular}

Sumber: data primer 2019 
Tabel .2 Analisa Hubungan Karakteristik Sosiodemografi Responden Dengan Kepatuhan Peserta PROLANIS

\begin{tabular}{|c|c|c|c|c|c|c|}
\hline \multirow{3}{*}{ Karakteristik } & \multicolumn{4}{|c|}{ Kepatuhan } & \multirow{3}{*}{$\begin{array}{c}\mathrm{P} \\
\text { value }\end{array}$} & \multirow{3}{*}{ OR (CI95\%) } \\
\hline & \multicolumn{2}{|c|}{ Tidak Patuh } & \multicolumn{2}{|c|}{ Patuh } & & \\
\hline & $\mathbf{n}$ & $\%$ & $\mathbf{n}$ & $\%$ & & \\
\hline \multicolumn{7}{|l|}{ Umur } \\
\hline Dewasa & 6 & 15.8 & 32 & 84.2 & \multirow{2}{*}{0.099} & \multirow{2}{*}{$\begin{array}{c}2.551(0.824- \\
7.895)\end{array}$} \\
\hline Lansia & 11 & 32.4 & 23 & 67.6 & & \\
\hline \multicolumn{7}{|l|}{ Jenis kelamin } \\
\hline Laki - laki & 6 & 37.5 & 10 & 62.5 & \multirow{2}{*}{0.183} & \multirow{2}{*}{$\begin{array}{c}2.455(0.733 \\
8.214)\end{array}$} \\
\hline Perempuan & 11 & 19.6 & 45 & 80.4 & & \\
\hline \multicolumn{7}{|l|}{ Tingkat Pendidikan } \\
\hline Rendah & 12 & 48.0 & 13 & 52.0 & \multirow{2}{*}{0.000} & \multirow{2}{*}{$\begin{array}{c}7.75(2.30- \\
26.12)\end{array}$} \\
\hline Tinggi & 5 & 10.6 & 42 & 89.4 & & \\
\hline \multicolumn{7}{|l|}{ Pekerjaan } \\
\hline Tidak bekerja & 9 & 40.9 & 13 & 59.1 & \multirow{2}{*}{0.022} & \multirow{2}{*}{$\begin{array}{c}3.63(1.16- \\
11.33)\end{array}$} \\
\hline Bekerja & 8 & 16.0 & 42 & 84.0 & & \\
\hline \multicolumn{7}{|l|}{ Dukungan Keluarga } \\
\hline Negatif & 10 & 66.7 & 5 & 33.3 & \multirow{2}{*}{0.000} & \multirow{2}{*}{$\begin{array}{c}14.28(3.76- \\
54.20)\end{array}$} \\
\hline Positif & 7 & 12.3 & 50 & 87.7 & & \\
\hline
\end{tabular}

Sumber: data primer 2019

Dengan menggunakan uji statistik analisis bivariat diketahui dari 38 responden yang merupakan kelompok dewasa, 32 orang (84.2\%) merupakan kelompok patuh dan 6 orang $(15.8 \%)$ kelompok tidak patuh. Sedangkan dari 37 responden kelompok lansia, 23 orang (67.6\%) merupakan kelompok patuh dan 11 orang (32.4\%) kelompok tidak patuh. Dengan menggunakan uji Chi Squre menunjukkan P-value $=0.09$ dimana lebih dari nilai kemaknaan yaitu 5\% (0.05), hal tersebut menunjukkan tidak terdapat hubungan yang signifikan antara usia dengan kepatuhan pesert a PROLANIS. Hasil penelitian menunjukkan tidak terdapat hubungan yang signifikan antara umur dengan kepatuhan peserta PROLANIS. Dari analisis di atas diperolah nilai $\mathrm{p}$-value $=0.099$.

Program pengelolaan penyakit kronis dirancang agar dapat memudahkan lansia dalam mengakses pelayanan kesehatan. Berdasarkan hasil penelitian di atas proporsi responden yang memanfaatkan prolanis pada kelompok usia pra lansia lebih besar dibandingkan kelompok usia lanisa yaitu sebesar 52.8\%. Hal ini dapat disebabkan oleh kondisi fisik pra lansia (dewasa) yang lebih baik jika dibandingkan dengan lansia sehingga untuk datang ke Puskesmas dapat dilakukan sendiri. Berbeda dengan lansia yang kondisi fisiknya sudah lemah sehingga menjadi lebih tergantung pada orang-orang disekitarnya. Khususnya keluarga. Selain faktor keluarga, ketidak teraturan lansia didalam memanfaatkan fasilitas Prolanis adalah lansia juga lupa dengan jadwal yang telah didtetapkan. Hal ini dikarenkan seiring dengan meningkatnya usia, tubuh akan mengalami perubahan yang menyebabkan involusi dan degradasi jaringan yang disertai penurunan fungsi organ tubuh. Umur atau 
usia adalah satuan waktu yang mengukur keberadaan suatu benda atau makluk, baik yang hidup maupun yang mati. Umur manusia diukur sejak dia lahir hingga waktu umur itu dihitung. Pada umumnya penyakit hipertensi dan DM berkembang pada saat umur seseorang mencapai paruh baya yakni cenderung meningkat khususnya lebih yang berusia 60 tahun keatas. Beberapa penelitian epidemiologi memperoleh hasil bahwa lanjut usia yang mengalami gangguan penyakit kronis cenderung mempengaruhi tingkat kualitas hidupnya (Sekardiani, 2019). Menurut (Anggraini, dkk, 2009) pada penelitiannya menunjukkan bahwa usia yang semakin bertambah membuat lansia tidak bisa aktif dalam kegiatan posyandu lansia. Pertambahan usia akan menimbulkan perubahan-perubahan pada struktur dan fisiologis sehingga menimbulkan kemunduran pada fisik dan psikis lansia. Usia yang semakin bertambah membuat lansia tidak bisa aktif dalam kegiatan posyandu lansia.

Dari pernyataan di atas peneliti berpendapat bahwa usia seseorang sangat berpengaruh terhadap aktivitas sehari hari. Lansia yang kondisi fisiknya sudah lemah akan menjadi lebih besar tergantung pada orang-orang disekitarnya. khususnya keluarga. Selain faktor keluarga, ketidak teraturan lansia didalam memanfaatkan fasilitas Prolanis adalah lansia juga lupa dengan jadwal yang telah ditetapkan. Berdasarkan jenis kelamin diketahui dari 16 responden yang berjenis kelamin laki-laki, 10 orang (62.5\%) merupakan kelompok patuh dan 6 orang (37.5\%) kelompok tidak patuh. Sedangkan dari 56 responden yang berjenis kelamin perempuan, 45 orang $(80.4 \%)$ merupakan kelompok patuh dan 11 orang (19.6\%) kelompok tidak patuh.

Dengan menggunakan uji Chi Squre menunjukkan P-value $=0.183$ dimana lebih dari nilai kemaknaan yaitu 5\% (0.05), hal tersebut menunjukkan tidak terdapat hubungan yang signifikan antara jenis kelamin dengan kepatuhan peserta PROLANIS. Sementara itu, hasil penelitian menunjukkan tidak terdapat hubungan yang signifikan antara jenis kelamin dengan kepatuhan peserta PROLANIS. Dari analisis di atas diperolah nilai $\mathrm{p}$-value $=0.183$. Hasil penelitian ini sejalan dengan penelitian Tawakal dkk (2015) dimana dari hasil penelitian diperoleh nilai $\mathrm{p}$-value $=1.000$. Hasil penelitian di atas sejalan juga dengan penelitian Rumengan, et al (2015) yang menunjukkan bahwa tidak terdapat hubungan yang bermakna antara jenis kelamin dengan pemanfaatan pelayanan kesehatan di Puskesmas.

Berdasarkan hasil penelitian di atas proporsi responden yang memanfaatkan prolanis pada responden perempuan lebih besar dibandingkan laki-laki yaitu sebesar 77.8\%. Hal ini dikarenakan sikap perempuan yang lebih peduli dengan kesehatannya dibandingkan dengan laki-laki. Perbedaan pola prilaku sakit juga dipengaruhi oleh jenis kelamin, perempuan lebih sering mengobatkan dirinya dibandingkan dengan laki-laki (Notoatmodjo, 2012). Hal ini dapat dikaitkan dengan ketersediaan waktu dan kesempatan bagi perempuan untuk datang ke Puskesmas lebih banyak dibandingkan dengan laki-laki. Namun saat ini perempuan tidak selalu memiliki kesersediaan waktu untuk datang ke Puskesmas karena banyak perempuan yang juga ikut bekerja/ mempunyai kesibukan seperti halnya laki-laki.

Menurut Anderson dalam (Notoatmodjo, 2012) jenis kelamin merupakan faktor predisposing dalam pemanfaatan pelayanan kesehatan. Jenis kelamin menunjukkan perbedaan biologis dari laki-laki dan perempuan. Perbedaan biologis dan fungsi biologis laki-laki dan perempuan tidak dapat dipertukarkan diantara keduanya, dan fungsinya tetap dengan laki-laki dan perempuan yang ada di muka bumi. Jenis kelamin kerap menjadi pembeda peran dan tugas dalam kehidupan sehari-hari maupun dalam hal pekerjaan. 
Dari pernyataan di atas peneliti berpendapat bahwa saat ini perempuan dan laki-laki tidak selalu memiliki kesersediaan waktu untuk datang ke Puskesmas karena sama-sama bekerja/ mempunyai kesibukan. Berdasarkan tingkat pendidikan diketahui dari 25 responden yang berpendidikan rendah, 13 orang (52.0\%) merupakan kelompok patuh dan 12 orang (48.0\%) kelompok tidak patuh. Sedangkan dari 47 responden yang berpendidikan tinggi, 42 orang $(89.4 \%)$ merupakan kelompok patuh dan 5 orang $(10.6 \%)$ kelompok tidak patuh.

Dengan menggunakan uji Chi Squre menunjukkan P-value $=0.000$ dimana kurang dari nilai kemaknaan yaitu 5\% (0.05), hal tersebut menunjukkan terdapat hubungan yang signifikan antara pendidikan dengan kepatuhan peserta PROLANIS. Dari analisis diatas didapatkan nilai $\mathrm{OR}=7.75$ yang menyatakan bahwa tingkat pendidikan tinggi memiliki kemungkinan 7.75 kali untuk patuh dalam kegiatan PROLANIS. Selanjutnya, hasil penelitian menunjukkan terdapat hubungan yang signifikan antara pendidikan dengan kepatuhan peserta PROLANIS. Dari analisis di atas diperolah nilai p-value $=0.000$ dengan nilai $\mathrm{OR}=7.75$. Hasil penelitian ini sejalan dengan penelitian (Riniasih \& Hapsari, 2020) dimana dari hasil penelitian terdapat hubungan yang signifikan antra tingkat pendidikan dengan peningkatan kualitas hidup peserta Prolanis.

Hasil penelitian ini berbanding terbalik dengan penelitian (Wibowo \& Fahrun, 2019) yang mengatakan tidak adanya pengaruh tingkat pendidikan terhadap kualitas hidup lansia, karena pendidikan pada dasarnya tidak hanya diperoleh dari bangku sekolah (formal)tetapi juga dilingkungan keluarga, masyarakat, dan dari media lainnya seperti majalah, berita dan lain lain. Berdasarkan penelitian yang dilakukan diketahui bahwa responden yang memiliki kepatuhan yang baik paling banyak terdapat pada responden berpendidikan tinggi (SMA dan PT). dari 47 responden yang berpendidikan tinggi, 42 orang (89.4\%) merupakan kelompok patuh sedangkan dari 25 responden yang berpendidikan rendah, 13 orang (52.0\%) merupakan kelompok patuh.

Pendidikan merupakan proses pembelajaran, pengetahuan, keterampilan dan kebiasaan sekelompok orang yang diturunkan dari satu generasi ke generasi berikutnya melalui pengajaran, pelatihan maupun penelitian. Makna secara luas terbatas pendidikan adalah usaha sadar yang dilakukan oleh keluarga, masyarakat dan pemerintah melalui kegiatan bimbingan, pengajaran dan atau latihan, yang berlangsung di sekolah dan luar sekolah untuk mempersiapkan peserta didik agar dapat memainkan perannya secara tepat dalam berbagai lingkungan hidup. Fungsi dari pendidikan sendiri adalah menghilangkan penderitaan rakyat dari kebodohan dan ketertinggalan. Diasumsikan bahwa orang yang berpendidikan akan terhindar dari kebodohan dan kemiskinan karena dengan modal ilmu pengetahuan dan ketrampilan yang diperolehnya melalui proses pendidikan, orang akan mampu mengatasi problema kehidupan yang dihadapinya. Semakin tinggi pendidikan seseorang, maka diasumsikan semakin tinggi pengetahuan, ketrampilan dan kemampuannya (Suardi, 2012).

(Kemenkes, 2013), menyatakan rendahnya tingkat pendidikan lansia dan banyaknya lansia akan dapat mempengaruhi aksebilitas lansia ke fasilitas kesehatan. Pernyataan tersebut juga sejalan dengan pendapat (Notoatmodjo, 2012) yang mengatakan tingkat pendidikan seseorang berpengaruh dalam memberikan respon terhadap sesuatu yang datang dari luar. Penelitian yang dilakukan oleh (Yusra, 2011) mengatakan bahwa tingkat pendidikan dapat memperngaruhi prilaku seseorang dalam mencari perawatan dan pengobatan penyakit yang dideritanya, serta memilih dan memutuskan tindakan terapi yang akan dijalaninya untuk mengatasi masalah kesehatannya. Tingkat pengetahuan yang kurang salah satu faktor yang menjadi penghambat dalam perilaku kesehatan karena mereka yang mempunyai pengetahuan rendah cenderung sulit untuk mengikuti anjuran 
dari petugas. Dari pernyataan di atas peneliti berpendapat bahwa pendidikan yang baik akan menghasilkan perilaku positif sehingga lebih terbuka dan obyektif dalam menerima informasi, khususnya informasi tentang penatalaksanaan penyakit. Orang yang berpendidikan akan terhindar dari kebodohan dan kemiskinan karena dengan modal ilmu pengetahuan dan ketrampilan yang diperolehnya melalui proses pendidikan. Seseorang yang mempunyai tingkat pendidikan tinggi akan memberikan respon yang lebih rasional dan lebih berpotensi dari pada mereka yang berpendidikan rendah atau sedang.

Berdasarkan pekerjaan diketahui dari 22 responden yang tidak bekerja, 13 orang (59.1\%) merupakan kelompok patuh dan 9 orang (40.9\%) kelompok tidak patuh. Sedangkan dari 50 responden yang bekerja, 42 orang $(84.0 \%)$ merupakan kelompok patuh dan 8 orang $(16.0 \%)$ kelompok tidak patuh. Dengan menggunakan uji Chi Squre menunjukkan P-value $=0.022$ dimana kurang dari nilai kemaknaan yaitu 5\% (0.05), hal tersebut menunjukkan terdapat hubungan yang signifikan antara pendidikan dengan kepatuhan peserta PROLANIS. Dari analisis diatas didapatkan nilai OR $=3.63$ yang menyatakan bahwa responden yang bekerja memiliki kemungkinan 3.63 kali untuk patuh dalam kegiatan PROLANIS.

Berdasarkan hasil penelitian menunjukkan terdapat hubungan yang signifikan antara pekerjaan dengan kepatuhan peserta PROLANIS. Dari analisis di atas diperolah nilai pvalue $=0.022$ dengan nilai $\mathrm{OR}=3.63$. Hasil penelitian ini sejalan dengan penelitian Rasajati (2015) dimana menunjukkan ada hubungan antara status pekerjaan dengan kepatuhan pengobatan dengan nilai $p$-value $=0,035(\mathrm{p}<0,05)$. Hasil penelitian ini tidak sesuai dengan penelitian yang dilakukan oleh Alphonce (2012) yang menunjukkan bahwa tidak ada hubungan antara pekerjaan dengan kepatuhan pengobatan pasien hipertensi dengan nilai $\mathrm{p}=0,908$. Hal ini dikarenakan orang yang bekerja cenderung memiliki sedikit waktu bahkan tidak ada waktu untuk mengunjungi fasilitas kesehatan (Notoatmodjo, 2012). Berdasarkan penelitian yang dilakukan diketahui bahwa responden yang memiliki kepatuhan yang baik paling banyak terdapat pada responden yang bekerja, dari 50 responden yang bekerja, 42 orang (84.0\%) merupakan kelompok patuh. sedangkan dari 22 responden yang tidak bekerja, 13 orang (59.1\%) merupakan kelompok patuh.

Pekerjaan adalah aktivitas yang dilakukan sehari-hari. Pekerjaan memiliki peranan penting dalam menentukan kualitas manusia. Pekerjaan membatasi kesenjangan antara informasi kesehatan dan praktek yang memotivasi seseorang untuk memperoleh informasi dan berbuat sesuatu untuk menghindari masalah kesehatan (Notoadmojo, 2012). Dari pernyataan di atas peneliti berpendapat bahwa pekerjaan menjadi salah satu faktor yang dapat mempengaruhi pengetahuan, dimana lingkungan kerja dapat menjadikan seseorang memperoleh pengalaman dan pengetahuan yang baik sevara langsung maupun tidak langsung.

Berdasarkan dukungan keluarga diketahui dari 15 responden yang mendapat dukungan negatif, 5 orang (33.3\%) merupakan kelompok patuh dan 10 orang (66.7\%) kelompok tidak patuh. Sedangkan dari 57 responden yang mendapat dukungan positif, 50 orang $(87.7 \%)$ merupakan kelompok patuh dan 7 orang (12.3\%) kelompok tidak patuh. Dengan menggunakan uji Chi Squre menunjukkan P-value $=0.000$ dimana kurang dari nilai kemaknaan yaitu $5 \%(0.05)$, hal tersebut menunjukkan terdapat hubungan yang signifikan antara dukungan keluarga dengan kepatuhan peserta PROLANIS. Dari analisis diatas didapatkan nilai $\mathrm{OR}=14.28$ yang menyatakan bahwa responden yang mendapatkan dukungan positif memiliki kemungkinan 14.28 kali untuk patuh dalam kegiatan PROLANIS. 
Berdasarkan hasil penelitian menunjukkan terdapat hubungan yang signifikan antara dukungan keluarga dengan kepatuhan peserta PROLANIS. Dari analisis di atas diperolah nilai $\mathrm{p}$-value $=0.000$ dengan nilai $\mathrm{OR}=14.28$. Hasil penelitian ini sejalan dengan penelitian (Tawakal \& Azkiya, 2020), dari hasil penelitian diperoleh nilai p-value $=0.042$ yang menunjukkan terdapat hubungan yang signifikan antara dukungan keluarga dengan pemanfaatan Prolanis. Keluarga adalah kelompok yang mempunyai peranan yang amat penting dalam mengembangkan, mencegah, mengadaptasi dan atau memperbaiki masalah kesehatan yang ditemukan dalam keluarga. Keluarga juga merupakan support System utama bagi lansia dalam mempertahankan kesehatannya (Mariam dkk, 2009). Bila salah satu atau beberapa anggota keluarga mempunyai masalah kesehatan, maka akan berpengaruh terhadap anggota keluarga lain serta keluarga lain disekitarnya (Mubarak \& Chayatin, 2009). Dukungan dari anggota keluarga pada penderita sangat mempengaruhi tingkat kepatuhan untuk berobat rutin, penderita yang mendapat dukungan keluarga akan lebih rutin berobat dan minum obat .

\section{Simpulan Dan Saran}

Keluarga dapat menjadi faktor yang sangat berpengaruh dalam menentukan keyakinan dan nilai kesehatan individu serta dapat juga menentukan tentang program pengobatan yang dapat mereka terima. Keluarga juga memberi dukungan dan membuat keputusan mengenai perawatan dari anggota keluarga yang sakit. Keluarga merupakan pihak yang yang paling dekat dengan pasien. Keluarga menjadi salah satu kunci seseorang berprilaku. Peran keluarga sangt penting dalam memberikan dukungan dan motivasi kepada pasien sehingga pasien patuh dalam menjalani terapi. Dukungan emosional seperti memberikan perhatian, mengingatkan jadwal pengobatan, ataupun menemani pasien pada saat berobat dapat meningkatkan kepatuhan pada pasien.

Bagi penderita diabetes mellitus tipe 2 dan hipertensi diharapkan dapat lebih meperhatikan konsumsi makanan, usahakan untuk mengurangi konsumsi makanan yang bercitarasa rasa manis yang berlebihan badi penderita diabtes mellitus, dan mengurangi makanan asin untuk penderita hipertensi, jadwal olahraga secara teratur hendaknya diterapkan setiap hari dan lebih meluangkan waktu untuk mengikuti kegiatan-kegiatan yang diadakan dalan program PROLANIS. Diharapkan dapat memberikan sumbangan informasi terhadap ilmu pengetahuan dan teknologi kedokteran (IPTEKDOK) khususnya tentang hubungan sosiodemografi dengan kepatuhan peserta PROLANIS.

\section{Daftar Rujukan}

Anggraini, A. D., Waren, A., Situmorang, E., Asputra, H., \& Siahaan, S. S. (2009). Faktorfaktor yang berhubungan dengan kejadian hipertensi pada pasien yang berobat $\mathrm{di}$ poliklinik dewasa puskesmas Bangkinang periode januari sampai juni 2008. Universitas Riau.

Fathoni, A. Z. (2017). Administrasi Kesehatan Program Pengelolaan Penyakit Kronis (Prolanis) Bpjs Kesehatan Di Puskesmas Kota Bandar Lampung (Studi pada Puskesmas Susunan Baru, Puskesmas Kedaton dan Puskesmas Sumur Batu).

Kemenkes, R. I. (2013). Riset kesehatan dasar 2013. Jakarta: Badan Penelitian Dan 
Pengembangan Kesehatan.

Mubarak, W. I., \& Chayatin, N. (2009). Ilmu kesehatan masyarakat: teori dan aplikasi. Jakarta: Salemba Medika, 393.

Notoatmodjo, S. (2012). Promosi kesehatan dan perilaku kesehatan. Jakarta: Rineka Cipta, 45-62.

Prastinawati.N.T. (2017). Faktor - Faktor Yang Mempengaruhi Peserta Dalam Mengikuti Kegiatan Aktivitas Klub Program Pengelolaan Penyakit Kronis Di Puskesmas II Denpasar Barat. Universitas Udayana.

Riniasih, W., \& Hapsari, W. D. (2020). Hubungan Tingkat Pendidikan Peserta Prolanis Dengan Peningkatan Kualitas Hidup Penderita Diabetes Melitus Di Fktp Purwodadi. The Shine Cahaya Dunia D-Iii Keperawatan, 5(1).

Sekardiani, N. L. P. (2019). Gambaran kualitas hidup peserta prolanis di puskesmas petang 1 kabupaten Badung Bali. MEDISAINS, 16(3), 132-136.

Suardi, M. (2012). Pengantar pendidikan teori dan aplikasi. Jakarta: Indeks.

Tawakal, F., \& Azkiya, A. (2020). Diagnosa Penyakit Demam Berdarah Dengue (DBD) menggunakan Metode Learning Vector Quantization (LVQ). JISKA (Jurnal Informatika Sunan Kalijaga), 4(3), 56-64.

Wibowo, F. T., \& Fahrun, N. R. (2019). Gambaran Kualitas Hidup Penderita Diabetes Melitus Di Wilayah Puskesmas Sukoharjo. Universitas Muhammadiyah Surakarta.

Wicaksono, S., \& Fajriyah, N. N. (2018). Hubungan keaktifan dalam klub prolanis terhadap peningkatan kualitas hidup diabetisi tipe 2. Jurnal Ilmiah Kesehatan (JIK), 11(1).

Wulandari, R., \& Antoni, E. (2017). Faktor Yang Berhubungan Dengan Kunjungan Peserta Ke Klub Prolanis Di Puskesmas Pekurun Kabupaten Lampung Utara 2016. JURNAL DUNIA KESMAS, 6(2).

Yusra, A. (2011). Hubungan antara dukungan keluarga dengan kualitas hidup pasien diabetes melitus tipe 2 di poliklinik penyakit dalam rumah sakit umum pusat fatmawati jakarta. Universitas Indonesia. 